\title{
EDUCAÇÃO E TRABALHO: A IMPORTÂNCIA E AS FORMAS DE VALORIZAR OS PROFISSIONAIS DA EDUCAÇÃO PÚBLICA NO ENSINO BÁSICO
}

\author{
Lincoln dos Reis ${ }^{1}$
}

RESUMO: O artigo consiste em investigar os dispositivos legais relativos a valorização do profissional da educação pública no ensino básico, propiciando a este profissional o conhecimento da legislação vigente sobre o tema, a qual serve de base para que seu direito possa ser pleiteado. Neste sentido, o artigo faz uma breve análise histórica e ontológica da relação entre a educação e o trabalho na sociedade com o objetivo de possibilitar uma reflexão sobre a evolução dos modos de produção e conscientizar a classe docente que sem luta dificilmente o desafio de valorizar o profissional da educação básica e pública será atingido. Destacando também o atual Governo e suas políticas neoliberais responsáveis por tornar as escolas públicas excludentes e a mercantilização da educação.

Palavras-chaves: Valorização professor. Professional da Educação. Educação Básica.

ABSTRACT: The article investigates the legal provisions related to the valorization of public education professionals in basic education, providing these professionals with knowledge of the current legislation on the subject, which serves as a basis for their right to be claimed. In this sense, the article makes a brief historical and ontological analysis of the relationship between education and work in society with the aim of enabling a reflection on the evolution of modes of production and making the teaching class aware that without a struggle it is difficult to face the challenge of valuing the professional education in basic and public education will be reached. Also highlighting the current Government and its neoliberal policies responsible for making public schools exclusionary and the commodification of education.

Keywords: Teacher Appreciation. Education Professional. Basic Education.

\section{INTRODUÇÃO}

Este Artigo se propõe a investigar os problemas e as dúvidas quanto ao futuro da educação pública, no ensino básico, tendo em vista as dificuldades e falta de

\footnotetext{
I Mestrado Profissional em Educação. Universidade de Uberaba. UNIUBE. Uberaba Brasil. Especialização em direito trabalhista. Faculdade Integrada de Jacarepaguá. FIJ. Rio de Janeiro. Brasil.
} 
compromisso dos governantes em colocar em prática o princípio da valorização do profissional da educação básica.

A investigação tem base na Constituição Federal de 1988, atualmente em vigor, cuja valorização dos profissionais da educação é tida como princípio, a qual preconiza como direito fundamental social a educação e o trabalho, conjuntamente com a aprovação do Plano Nacional de Educação através da Lei no 13.005/2014 (Brasil, 2014), que entrou em vigor em $25 / 07 / 2014$, trazendo como uma de suas diretrizes a valorização dos profissionais da educação.

Precedentemente, com a aprovação do Plano Nacional de Educação, o Brasil, por meio de seus Governantes, finalmente reconhece a importância da educação no País, diante da obvia carência do ensino básico e os rumos desastrosos em que a educação pública do ensino básico caminha em direção ao futuro, fato este comentados rotineiramente nos telejornais, a exemplo do programa Fantástico apresentado pela rede Globo $\left(2019^{2}\right)$, onde foram apresentados alguns casos de professores sendo atacados na sala de aula por alunos, e na sequência feitos alguns prequestionamentos do repórter em relação a falta de valorização do profissional do ensino básico por parte dos governantes e a falta de apoio da sociedade, bem como o questionamento se vale a pena sacrificar pela educação em troca das péssimas condições de trabalhos e os baixos salários.

Posteriormente e na contramão, no governo de Michel Temer, com a aprovação da Emenda Constitucional número 95/2016, que instituiu o teto dos gastos federais, esta aparece impossibilitando a implementação do Plano Nacional da Educação, principalmente em relação a sua "meta 20"3 (Brasil, 2014), que busca ampliar o investimento público em educação, assumindo o compromisso de atingir até IO\% do PIB até o final de 2014.

\footnotetext{
${ }^{2}$ Disponível em : https://globoplay.globo.com/v/7679653/, programa da Globo de 2 de junho de 2019, acesso em 12/05/2021.

${ }^{3}$ Meta 20: ampliar o investimento público em educação pública de forma a atingir, no mínimo, o patamar de 7\% (sete por cento) do Produto Interno Bruto - PIB do País no 5 o (quinto) ano de vigência desta Lei e, no mínimo, o equivalente a ro\% (dez por cento) do PIB ao final do decênio. (Brasil, 2014)
} 
$\mathrm{Na}$ sequencia com a posse do atual Governo e suas políticas neoliberais, fundadas na grande crise política, econômica e social que o País vem atravessando, o Estado tem como objetivo induzir a sociedade a aceitar o desmonte dos sistemas públicos de ensino, visando entregá-lo ao capital, sob a alegação de garantir um melhor padrão de qualidade, no entanto, esta modalidade de privatização, segundo Peroni $(2018)^{4}$ pode provocar graves consequências à democratização da educação, principalmente pelo fato do Estado ser o principal responsável pelo direito a educação, pois permitir que o setor privado assuma estas políticas educacionais é desvincular a educação do direito social, permitindo desta maneira que o ensino básico deixe de fazer parte do campo social e político e passe a ser tratada como mercadoria, ocorrendo assim a mercantilização da educação, preocupação esta vista nas palavras de GENTILI:

(...) depois do dilúvio neoliberal, nossas escolas serão muito piores do que já são agora. Não se trata apenas de um problema de qualidade pedagógica, ainda que também o seja. Trata-se de um problema político e ético: nossas escolas serão piores porque serão mais excludentes. (GENTILI,I998, p. 33).

Nota-se que mercantilização da educação vem ocorrendo devido às exigências do capital e cortes de recursos públicos, que influência diretamente na desvalorização do profissional da educação, favorecendo os grupos econômicos que estão preocupados unicamente em formar jovens para servir ao capital, ou seja, educados na perspectiva de ser um fator de produção, fato observado por SADER:

No reino do capital, a educação é, ela mesma, uma mercadoria. Daí a crise do sistema público de ensino, pressionado pelas demandas do capital e pelo esmagamento dos cortes de recursos dos orçamentos públicos. (SADER, 2008 , p. I).

\footnotetext{
${ }^{4}$ Disponível em

https: //www.google.com/url?sa=t\&rct=j\&q=\&esrc=s\&source= web\&cd= $=$ \& $c a d=r j a \& u a c t=8 \& v e d=2 a h$ UKEwijhamMv7zjAhVBIbkGHZd9AvMQFjAAegQIARAC\&url=http\%3A\%2F\%2Fwww.curriculos emfronteiras.org\%2Fvolı8issiarticles\%2Fperoni.pdf\&usg=AOvVawo3A-uupDCzooymO7xxCxpt, acesso em $17 / 05 / 2021$.
} 
Diante deste cenário, este artigo procura questionar a relação entre a educação, o trabalho e a valorização do profissional do ensino básico, tendo como objetivo inicial fazer uma breve análise histórica e ontológica da relação entre a educação e o trabalho na sociedade, no sentido de melhor compreender a evolução do modo de produção capitalista, o qual é possuidor de um caráter dominador e não humanizador, e principalmente por considerar o fato do profissional da educação básica ser parte integrante de uma relação de trabalho. Neste contexto, o artigo visa demonstrar que a valorização dos profissionais do ensino básico aparece como peça fundamental para o desenvolvimento da educação no País, e nessa perspectiva destaca a influência da educação na concretização do direito ao trabalho de forma digna.

Neste sentido, a questão norteadora do presente estudo é apresentar as principais formas de valorização do profissional da educação, bem como comentar a legislação vigente e sua efetividade, ou seja, a atuação prática e concreta da norma jurídica que regula o assunto, pois valorizar o profissional da educação básica é dar efetividade aos direitos sociais garantidos constitucionalmente, é ter na educação e no trabalho a principal ferramenta para a conquista de uma sociedade desenvolvida e que preserve a dignidade humana.

\section{OS ASPECTOS HISTÓRICOS E ONTOLÓGICOS NA RELAÇÃO DO TRABALHO E A EDUCAÇÃO NA SOCIEDADE, BEM COMO OS MODOS DE PRODUÇÃO DO TRABALHO AO LONGO DA HISTÓRIA.}

Tendo em vista que o profissional da educação básica ser parte integrante de uma relação de trabalho e por esta relação de trabalho ocorrer em um ambiente escolar público, onde o tema "educação" se apresenta como uma das formas de valorizar este profissional, sem dúvida vale a pena fazer uma breve análise histórica e ontológica desta relação, bem como analisar a relação da educação e do trabalho como fator responsável pela valorização deste profissional.

De acordo com Saviani a relação entre a educação e o trabalho surge com o nascimento do ser humano, no exato momento que este é inserido na natureza, o 
qual passa a existir porque dispõem de corpo e funções biológicas, neste instante o homem não tem sua existência garantida pela natureza, fato que os diferenciam dos demais animais. Diante desta necessidade, para garantir sua existência, ao nascer o ser humano é obrigado a se transformar em um novo tipo de ser, o ser social, cujas peculiaridades não estão definidas em sua genética, mas sim na necessidade básica de viver em sociedade.

Afirma Saviani que na base desta transformação, este ser social se torna no ser do trabalho, pois passa a ter necessidade de produzir sua existência, pois enquanto os animais se adaptam a natureza os homens têm a necessidade de fazer o contrário, adaptar a natureza as suas necessidades, transformando-a através do trabalho, para garantir sua sobrevivência. Nesta perspectiva o trabalho torna-se essencial para manter a vida humana, destacando-se aqui como precursor da educação, cujo momento pode ser entendido como ponto de partida do vínculo entre a educação e o trabalho, a qual esta relação passa a garantir o processo da existência do homem.

Neste sentido, constata que a produção do homem é ao mesmo tempo sua formação, segundo Saviani, “Os homens aprendiam a trabalhar trabalhando. Lidando com a natureza, relacionando-se uns com os outros, os homens educavamse e educavam as novas gerações." (SAVIANI, 2007, p.154).

Nesta perspectiva, por ser o homem um ser social, o trabalho era feito de forma coletiva, a terra era apropriada de forma coletiva, onde os homens produziam suas necessidades em comum e se educavam no mesmo processo, garantindo assim sua existência.

Posteriormente, percebe que a apropriação privada da terra e o desenvolvimento da produção provoca a divisão daquela sociedade, fato que dá origem a classes dos proprietários e dos não proprietários. A partir deste momento a forma de trabalho passa a ser dividida, muda-se o modo de todos em relação ao trabalho, o que possibilita que os proprietários de terras passem a viver do trabalho alheio. 
Diante deste fato, a partir do momento em que os proprietários de terra passam a ter mais tempo livre um novo tipo de educação começa a existir, pois se antes a educação coincidia com o próprio processo do trabalho, agora com uma parcela da população podendo viver do ócio, nasce uma nova educação para esta camada social, surgindo uma nova escola para onde iam os filhos de quem não precisavam trabalhar.

Esta nova escola tem sua origem com a divisão do trabalho, que segundo o entendimento de Marx e Engels "A divisão do trabalho só surge efetivamente, a partir do momento em que se opera uma divisão entre o trabalho material e intelectual..." (Marx; Engels, 20II, p.26), momento em que surge um novo tipo de educação destinada a classe dominante, que passa a ser desenvolvida no campo das ideias, na arte das palavras, na música, na observação da natureza. Enquanto a educação da classe dominada continuava sendo a mesma educação relaciona com o processo do trabalho.

Diante do cenário histórico desta relação percebe-se que o trabalho passa por várias transformações ao longo do tempo, ou seja, passa por vários modos de produção, demonstrando as maneiras pela qual a sociedade se organiza para garantir a produção de suas necessidades diante do seu nível de desenvolvimento e de suas forças produtivas, ou seja, para permanecerem vivos, produzindo e reproduzindo os meios que satisfação suas necessidades básicas, conceito este desenvolvido por Marx e Engels ao dizer que "a produção da própria vida material, e este é, sem dúvida, um ato histórico, uma condição fundamental de toda a história, que ainda hoje, assim como há milênios, tem de ser cumprida diariamente, a cada hora, simplesmente para manter os homens vivos." (MARX; ENGELS, 2007, p. 33).

No modo de produção primitivo, ou seja, produção comunitária, os homens trabalhavam em conjunto e usufruíam de seus esforços, todos se beneficiavam da produção, neste momento histórico não existia o conceito de propriedade privada, o trabalho era desenvolvido de forma natural, onde "... na produção social para sua existência, os homens estabelecem entre si relações determinadas, necessárias e 
independentes de suas vontades.” (MARX, 1977, p. 24-25), de forma inconsciente e alheia à sua vontade de maneira a garantir sua existência.

Já no modo de produção escravista, surge o Estado, instrumento da classe dominante, onde o interesse da coletividade trabalho deixa de ser defendidos, em benefício da classe dominante. Período em que a formação do trabalhador/escravo se dava no local e no exercício do trabalho. A educação da classe dominante era voltada para a filosofia, retórica e a política, entre outras áreas do conhecimento. Os escravos eram considerados meios de produção, este modo de produção surge com o crescimento do conhecimento sobre a produção, onde a sociedade passa a produzir além do necessário para sua sobrevivência, que segundo Marx (1996), nos quadros do escravismo antigo à produção estava orientada em um sistema para a exploração de mais-valia.

Quanto ao modo de produção feudal este baseia-se na relação de troca, onde o senhor feudal cede terras para que os servos produzam, em troca de casa e comida. Neste período a Igreja se destacava como veículo da legitimação das relações sociais e de produção. O modo de produção feudal o trabalho não era uma atividade para o clero e os nobres, e nesta mesma linha de raciocínio a educação também se diferenciava para os que trabalham e os que se apropriavam do trabalho alheio, "O Feudalismo sugere fundamentalmente a persistência de formas de coerção direta muito variáveis, traduzidas pelo trabalho compulsório sob relações de dominação e de servidão." (Oliveira, 1987, p.48).

Com a decomposição do feudalismo, no pré-capitalismo, com o desenvolvimento de novas formas de organização econômica e social surge o modo de produção capitalista, baseado nos meios de produção da propriedade privada da burguesia, onde os trabalhadores produziam em troca de salário, momento em que surge o Estado administrando a nova forma adquirida pelo homem de garantir sua subsistência, cujo “... sistema capitalista requeria [...] uma posição servil da massa do povo, sua transformação em trabalhadores de aluguel e a de seus meios de trabalho em capital” (MARX, 1996, p. 345). 
Neste contexto o Estado é fundamental para garantir a manutenção da ordem e a expansão e o acumulo do capital. Nesta nova relação de trabalho:

Assim como os trabalhadores dependem do mercado para vender sua mão-de-obra como mercadoria, os capitalistas dependem dele para comprar força de trabalho e os meios de produção, bem como para realizar seus lucros vendendo os produtos ou serviços produzidos pelos trabalhadores. (WOOD, 2001, p.78).

Observa-se que ao longo da história a educação e o trabalho transformam-se diante das novas formas do ser humano organizar a produção, e é nessa concepção que são criadas as políticas educacionais para servir o capital com a formação de mão-de-obra eficiente para o mercado, sem a preocupação de uma educação integral que valorize o indivíduo.

E é neste contexto que valorizar o profissional da educação pública ser uma das ferramentas de garantir um ensino democrático capaz de transformar a sociedade, fato descrito por Gramsci ao criticar o ensino profissional afirmando que:

[...] a tendência democrática, intrinsecamente, não pode consistir apenas em que um operário manual se torne qualificado, mas em que cada 'cidadão' possa se tornar 'governante' e que a sociedade o coloque, ainda que 'abstratamente', nas condições gerais de poder fazê-lo. (Gramsci, 1978, p. 137).

\section{A IMPORTÂNCIA DA VALORIZAÇÃO DO PROFISSIONAL DA EDUCAÇÃO BÁSICA.}

Diante do tema tratado anteriormente observa-se que a educação é um fenômeno próprio dos seres humanos, onde a prática da educação existiu antes mesmo que tivéssemos um conhecimento formalizado sobre a educação, neste sentido, podemos afirmar que a profissão docente é um dos ofícios mais antigos e importantes do mundo, e é neste sentido que este capítulo dedica em demonstrar a importância do papel do professor na construção e preparação do indivíduo para que este seja um cidadão crítico, autônomo, participativo e produtivo. Vivemos em uma sociedade que exige do cidadão o saber pensar, questionar, duvidar, raciocinar, aprender e de ensinar, onde o Estado defende a educação como fator 
imprescindível na formação do cidadão, mas o que vemos na prática e a deficiência da educação pública e sua desvalorização e com ela também o papel do professor.

Para Kenski :

O papel do professor em todas as épocas é ser o arauto permanente das inovações existentes. Ensinar é fazer conhecido o desconhecido. Agente das inovações por excelência o professor aproxima o aprendiz das novidades, descobertas, informações e notícias orientadas para a efetivação da aprendizagem. (Kenski, 200I, p.I03).

Baseado na reflexão de Gramsci apesar da escola ter função reprodutora da sociedade, está também é capaz de causar superação nos indivíduos, no tocante à luta por uma sociedade melhor : “(...) a escola deve ser "capaz” de levar os indivíduos das mais diferentes classes sociais, sobretudo das classes subalternas, a uma condição de esclarecimento e de conhecimento de seus direitos e deveres em uma sociedade moderna." (MOCHCOVITCH, I988, p. 7).

Pautado em (Saviani, 2006) inicialmente a escola se destinava a uma elite da sociedade que possuía condições para manter os estudos, momento em que classe de docentes era em sua maioria composta pelo sexo feminino, também da elite, e somente com a promulgação da Constituição Federal de 1988 é que a educação escolar passou a ser um direito de todos, de forma gratuita e obrigatória, onde a necessidade de docentes se torna fundamental para manter o ensino básico, no entanto, o que se percebe é um aumento na ausência destes profissionais para atuarem no magistério, que de acordo com Libâneo (2007) é devido.

[...] a desvalorização econômica e social do magistério, além de comprometer o status social da profissão, também retira o status acadêmico dos campos de conhecimentos que the correspondem, tornando o ensino uma linha de pesquisa menos nobre. Não é casual, por exemplo, a pouca valorização dos cursos de licenciatura nas universidades e a insuficiência de pesquisas nesse campo. (Libâneo, 2007, p.93).

Constata-se que a desvalorização do docente no ensino básico interfere e reflete na sua formação e no seu comprometimento com o ensino e a aprendizagem dos alunos. O fato é percebido diante da procura de vagas em outras áreas, em 
profissões que valorizam mais o trabalhador e assim demandam maior procura de vagas e consequentemente uma exigência maior no nível de formação acadêmica, caso que não ocorre no setor da educação pública, tendo em vista que a procura cai na medida inversa da formação do candidato diante da desvalorização do profissional da educação.

A desvalorização tem grande impacto na motivação quando se discute a formação deste profissional da educação básica, pois uma vez que não é dada condições dignas de subsistência a este profissional, dificilmente a sua formação será completa, onde segundo Cunha (2010) os professores apontam três pontos importantes relacionado ao tema, que são : "a desvalorização do magistério, estrutura do ensino e condições de trabalho" (Cunha, 2010, p.Io9-III), sendo o primeiro ponto a questão salarial a qual os professores reconhecem com certa mágoa a sua desvalorização; o segundo ponto a atual estrutura do ensino básico, determinada pelo modelo de escola e da legislação contemporânea e o terceiro e último ponto as condições de trabalho, bem como espaços físicos, materiais didáticos, falta de bibliotecas que impossibilitam um ensino de melhor qualidade

Motivar este profissional envolve uma ação conjunta entre fatores externos tais como estímulo e incentivo, como também, fatores internos que envolvem a autorrealização e o interesse do indivíduo de investir em seu potencial.

Com relação ao aspecto salarial, quando comparamos um professor a um outro profissional de nível superior, percebe-se que o profissional do ensino básico tem seus vencimentos muito inferior a este. Fato que Gatti e Barretto (2009) concordam ao explicitar que "os salários recebidos pelos professores não são tão compensadores, especialmente em relação as tarefas que lhe são atribuídas" (Gatti; Barretto , 2009, p. 247). Percebe que atualmente menos profissionais procuram a carreira do magistério, fato que fica constatado no baixo índice de procura pela carreira de licenciatura, que gradativamente vem sofrendo quedas.

Diante desta situação os profissionais do ensino básico passam uma imagem triste a sociedade, que segundo Vicentini e Lugli (2009) este educador é visto como 
sendo "um profissional mal preparado e com uma remuneração insuficiente que goza de pouco prestigio na sociedade e cuja legitimidade está sob constante ameaça.". (VICENTINI; LUGLI, 2009, p. 156).

Neste contexto, não há como avançar profissionalmente na carreira docente diante do pessimismo e desprezo com a profissão docente, cujos fatos acima Libâneo(200I) corrobora e aponta que:

\begin{abstract}
A desprofissionalização afeta diretamente o status social da profissão em decorrência dos baixos salários, precária formação teórico-prática, falta de carreira, deficientes condições de trabalho. Com o descrédito da profissão, as consequências são inevitáveis: abandono de sala de aula em busca de outro trabalho, redução da procura dos cursos de licenciatura, escolha de cursos de licenciatura ou pedagogia como ultima opção (em muitos casos, são alunos que obtiveram classificação mais baixa no vestibular), falta de motivação dos alunos matriculados para continuar o curso (LIBANEO, 2001, p. 43).
\end{abstract}

Tem-se no professor a responsabilidade de preparar o indivíduo para ser um cidadão ativo dentro da sociedade, portanto valorizar o profissional da educação pública básica é valorizar a escola pública, é garantir as futuras gerações o saber crítico, é evitar que o trabalhador tenha sua existência de forma alienada, que segundo (Saviani, 2005, p. 76) ocorre "Na sociedade capitalista, a tendência é tornálo propriedade exclusiva da classe dominante.".

Temos na educação pública uma das políticas de maior importância para mudança nos padrões das desigualdades no Brasil, mas para obter êxito os profissionais da educação básica necessitam de motivação para se inserirem e permanecerem na profissão, fato que ocorrerá somente com medidas que estimulem e valorizem estes profissionais do ensino básico.

Não basta a Constituição Federal de 1988, prevê em seu Artigo 205 ser "A educação, direito de todos e dever do Estado e da família" (Brasil, i988) a qual deverá ser "...promovida e incentivada com a colaboração da sociedade, visando ao pleno desenvolvimento da pessoa, seu preparo para o exercício da cidadania e sua qualificação para o trabalho.” (Brasil, I988).

É preciso garantir as finalidades do art. 22 da LDBE, onde "A educação básica tem por finalidades desenvolver o educando, assegurando-lhe a formação comum indispensável para o exercício da cidadania e fornecer-lhe meios para progredir no trabalho e estudos posteriores." (Brasil, 2016).

\title{
3 OS PROFISSIONAIS DA EDUCAÇÃO BÁSICA E A LEGISLAÇÃO VIGENTE EM RELAÇÃO A VALORIZAÇÃO DESTE PROFISSIONAL.
}

São considerados profissionais da educação escolar básica, os professores e 
trabalhadores da educação, conforme disposto no (artigo 6I, da Lei nº 9394/96)5.

Quanto ao direito à valorização desta categoria profissional e sua previsão legal, temos inicialmente a Constituição Federal de 1988 (CF/88, art. 206, inciso "V") 6 , bem como nas Leis subsequentes: Lei de Diretrizes e Bases da educação (LDBE 9.394/96, art. 67)7 e a Lei que aprovou o Plano Nacional de Educação (Lei 13005/2014, art. 2o., inciso "IX") ${ }^{8}$, que estabelecem o direito a valorização deste profissional e as suas formas de valorização.

\footnotetext{
${ }^{5}$ Art. 6r. Da Lei 9394/96 - Consideram-se profissionais da educação escolar básica:

I - os professores habilitados em nível médio ou superior em cursos reconhecidos de instituições credenciadas, para o exercício da docência na educação infantil e nos ensinos fundamental e médio; II - os professores em efetivo exercício da docência em instituições públicas e privadas credenciadas, que oferecem alguma das etapas ou modalidades da educação básica, ainda que não habilitados mas que comprovem estar matriculados em cursos de formação profissional para o magistério;

III - os trabalhadores em educação portadores de diploma de curso de pedagogia, com habilitação em área pedagógica, bem como de mestrado ou doutorado nas mesmas áreas, em exercício ou não na educação básica;

IV - os trabalhadores em educação, em efetivo exercício em rede pública ou privada, portadores de diploma de curso técnico ou tecnológico em área pedagógica ou afim, obtido em instituição credenciada, reconhecidos como profissionais da educação pelos sistemas de ensino; $\mathrm{V}$ - os trabalhadores em educação, quando em exercício na educação básica e matriculados nos cursos a que se refere o inciso anterior. (Brasil, 1996).
}

${ }^{6}$ CONSTITUIÇÃO FEDERAL 1988 - CAPÍTULO III - DA EDUCAÇÃO - DA CULTURA E DO DESPORTO -Seção I - DA EDUCAÇÃO,

Art. 206. O ensino será ministrado com base nos seguintes princípios:

$\mathrm{V}$ - valorização dos profissionais da educação escolar, garantidos, na forma da lei, planos de carreira, com ingresso exclusivamente por concurso público de provas e títulos, aos das redes públicas; (Brasil, 1988).

7 Lei de Diretrizes e Bases 9.394/96 - art. 67. Os sistemas de ensino promoverão a valorização dos profissionais da educação, assegurando-lhes, inclusive nos termos dos estatutos e dos planos de carreira do magistério público:

I - ingresso exclusivamente por concurso público de provas e títulos;

II - aperfeiçoamento profissional continuado, inclusive com licenciamento periódico remunerado para esse fim;

III - piso salarial profissional;

IV - progressão funcional baseada na titulação ou habilitação, e na avaliação do desempenho;

V - período reservado a estudos, planejamento e avaliação, incluído na carga de trabalho;

VI - condições adequadas de trabalho.

${ }^{8}$ Lei que aprovou o Plano Nacional de Educação (Lei 13005/2014, art. 2º., IX)

Art. 2 o São diretrizes do PNE:

IX - valorização dos (as) profissionais da educação; (Brasil, 1996). 
De acordo com a legislação citada nota-se que os professores são considerados trabalhadores, ou seja, profissionais da educação, que segundo Monlevade para um sujeito ser considerado profissional serão necessários três itens fundamentais : "sua especialização e competência num determinado saber ou fazer; o fato de esta pessoa sobreviver deste trabalho; o fato de sua especialidade ser identificada e reconhecida socialmente.“. (MONLEVADE, 20II, p.I2), portanto valorizar estes profissionais é respeitar a legislação vigente.

Conforme o artigo 206, inciso "V", da Constituição Federal de I988 (Brasil, 1988) e o artigo 67 da Lei de Diretrizes e Bases 9.394/1996 (Brasil, 1996) temos como principais formas de valorização destes profissionais : $O$ plano de carreira, o ingresso exclusivamente por concurso público de provas e títulos, o piso salarial, progressão funcional e carga horária; sua formação inicial e continuada e condições adequadas de trabalho. De acordo com Leher(2010) a valorização do magistério pode ser definida e discutida em duas dimensões, sendo elas:

OBJETIVAS - regime de trabalho; piso salarial profissional; carreira docente com possibilidade de progressão funcional; concurso público de provas e títulos; formação e qualificação profissional; tempo remunerado para estudos, planejamento e avaliação, assegurado no contrato de trabalho, e condições de trabalho e SUBJETIVAS - reconhecimento social, autorrealização e dignidade profissional. (LEHER, 2010, p. 45).

A Constituição Federal de 1988 (Brasil, 1988) determina que o ensino deverá ser ministrado com qualidade 9 e por ser o profissional da educação básica parte do ensino, valorizar este profissional torna-se fundamental para garantir uma educação de qualidade, neste sentido, a seguir abordaremos as formas de valorização e seus aspectos legais.

De acordo com a determinação do inciso "I” do artigo 67 da Lei de Diretrizes e Bases da Educação 9.394 de 1996 (Brasil, 1996), deverá o ingresso dos profissionais do magistério ser feito exclusivamente por concurso público de provas e títulos, fator este imprescindível à garantia da igualdade e combate a contratações irregulares.

9 206. O ensino será ministrado com base nos seguintes princípios: VII - garantia de padrão de qualidade. (Brasil, 1988). 
Observa-se que a desobediência deste preceito legal acarreta a precarização da profissão, além de não ser o meio correto de provimento dos cargos destes profissionais, conforme previsto no (art. 37, incisos I e II, da CF/88) ${ }^{\mathrm{Io}}$.

Outro importante passo foi à promulgação da Lei II.738/2008 ${ }^{\text {II }}$ que instituiu o Piso Salarial (vencimento inicial) e definiu a Carga Horária para os profissionais do magistério da educação básica. Onde ficou determinado que a União, os Estados, o Distrito Federal e os Municípios não poderão fixar o vencimento inicial das carreiras do magistério público da educação básica, para a jornada de, no máximo, 40 horas semanais com valor abaixo do piso salarial, não havendo vedação para carga horária inferior a 40 horas, desde que, o valor mínimo do vencimento seja proporcional ao piso salarial nacional. Conforme divulgado no site do $\operatorname{MEC}^{12}$ (2019, online), hoje o piso nacional do magistério para o ano de 2019, para uma jornada de 40 horas semanais é de $R \$ 2.557,74$ desde janeiro.

Io Art. 37. A administração pública direta e indireta de qualquer dos Poderes da União, dos Estados, do Distrito Federal e dos Municípios obedecerá aos princípios de legalidade, impessoalidade, moralidade, publicidade e eficiência e, também, ao seguinte :

I - os cargos, empregos e funções públicas são acessíveis aos brasileiros que preencham os requisitos estabelecidos em lei, assim como aos estrangeiros, na forma da lei;

II - a investidura em cargo ou emprego público depende de aprovação prévia em concurso público de provas ou de provas e títulos, de acordo com a natureza e a complexidade do cargo ou emprego, na forma prevista em lei, ressalvadas as nomeações para cargo em comissão declarado em lei de livre nomeação e exoneração; (Brasil, 1988).

II LEI № II.738, DE I6 DE JULHO DE 2008.

Art. ${ }^{\circ}$ Esta Lei regulamenta o piso salarial profissional nacional para os profissionais do magistério público da educação básica a que se refere a alínea " $e$ " do inciso III do caput do art. 6o do Ato das Disposições Constitucionais Transitórias.

Art. $2^{\circ} \mathrm{O}$ piso salarial profissional nacional para os profissionais do magistério público da educação básica será de R\$950,0o (novecentos e cinqüenta reais) mensais, para a formação em nível médio, na modalidade Normal, prevista no art. 62 da Lei $\mathrm{n}^{\circ}$ 9.394, de 20 de dezembro de 1996 , que estabelece as diretrizes e bases da educação nacional.

$\S$ I $^{\circ}$ O piso salarial profissional nacional é o valor abaixo do qual a União, os Estados, o Distrito Federal e os Municípios não poderão fixar o vencimento inicial das Carreiras do magistério público da educação básica, para a jornada de, no máximo, 40 (quarenta) horas semanais.

$\S 3^{\circ}$ Os vencimentos iniciais referentes às demais jornadas de trabalho serão, no mínimo, proporcionais ao valor mencionado no caput deste artigo.

$\S 4^{\circ} \mathrm{Na}$ composição da jornada de trabalho, observar-se-á o limite máximo de $2 / 3$ (dois terços) da carga horária para o desempenho das atividades de interação com os educandos.

Art. $5^{\circ} \mathrm{O}$ piso salarial profissional nacional do magistério público da educação básica será atualizado, anualmente, no mês de janeiro, a partir do ano de 2009. (Brasil, 2008).

I2 Disponível em : http://portal.mec.gov.br/component/content/article?id=72571, acesso em 14/o7/2019. (MEC, 2019, online). 
Quanto à carga horária, em seu artigo 2º, parágrafo $4^{\underline{0}}$ (Brasil, 1996), ficou determinado que na composição da jornada de trabalho, observar-se-á o limite máximo de $2 / 3$ da carga horária para o desempenho das atividades de interação com alunos, devendo no mínimo $1 / 3$ desta jornada de trabalho ser destinada às chamadas atividades extraclasse, que conforme inciso "V" do artigo 67 da Lei de Diretrizes e Bases da Educação 9.394 de $1996^{6}$, determinou que deverá ser reservado dentro da carga horária de trabalho um período para estudo, planejamento e avaliação.

De acordo com o inciso II, do artigo 67, da a Lei de Diretrizes e Bases da Educação Nacional ${ }^{6}$ (Brasil, 1996) a política de aperfeiçoamento profissional continuado é vista como forma de valorização do profissional do ensino básico, e neste sentido, o parágrafo $\mathrm{I}^{\mathrm{o}}$ do artigo 62 da respectiva Lei institui que cabe a "União, o Distrito Federal, os Estados e os Municípios, em regime de colaboração, deverão promover a formação inicial, a continuada e a capacitação dos profissionais de magistério."

Neste sentido, Libâneo afirma que:

\begin{abstract}
A escola de hoje precisa propor respostas educativas e metodológicas em relação a novas exigências de formação postas pelas realidades contemporâneas como a capacitação tecnológica, a diversidade cultural a alfabetização tecnológica, a super informação, o relativismo ético, a consciência ecológica. Pensar num sistema de formação de professores supõe, portanto, reavaliar objetivos, formas de organização do ensino, diante da realidade em transformação. (LIBÂNEO, 20oI, p. 8o).
\end{abstract}

No entanto, este processo de formação inicial e continuada deve buscar as reais necessidades de aperfeiçoamento dos profissionais da educação básica, buscando elevar o patamar de qualidade do ensino público e democrático, aprimorando as competências que deverão impactar na prática pedagógica que possibilitará um ensino transformador.

Tendo em vista que a licença remunerada para fins de formação inicial e/ou continuada ter sido negligenciada pelo Estado, cabe ao sistema de ensino propiciar

${ }^{13}$ LDB 9394/96 Art. 62. - § I - A União, o Distrito Federal, os Estados e os Municípios, em regime de colaboração, deverão promover a formação inicial, a continuada e a capacitação dos profissionais de magistério. (Brasil, 1996). 
este direito ou caso contrário deverá o próprios profissionais da educação buscar este direito, mesmo que tenha que acionar o judiciário, exemplo do mandado de segurança interposto, por um professor, para garantir o direito a licença remunerada, fato que pode ser consultado no site Tribunal de Justiça do Estado da Bahia TJ-BA Mandado de Segurança : MS ooro783-46.2017.8.05.00oo ${ }^{14}$.

Quanto a progressão funcional no serviço público, relativo aos cargos efetivos, estas deverão ocorrer de forma escalonada com base na titulação, tempo de serviço, desempenho profissional. A exemplo da Lei 12.772/2012 (Brasil, 2012), que dispões sobre o Plano de Carreira e Cargos de Magistério do Ensino Básico, Técnico e Tecnológico e sobre o Plano de Carreiras de Magistério do Ensino Básico Federal, artigo $\mathrm{I} 6$, inciso I e II ${ }^{15}$.

A falta de condições adequadas para o trabalho é outro fator da precarização da profissão docente, inicialmente em relação ao excesso da carga horária, uma vez que a maioria dos professores da educação básica são obrigados a se desdobrarem em jornadas duplas ou até mesmo triplas para manter o nível socioeconômico. Outros problemas relacionados com as condições de trabalho estão na falta de condições ambientais físicas e materiais, número excessivo de alunos por sala de aula, má condição acústica da sala, violência na escola, pouco tempo para o preparo das aulas, ritmo acelerado de trabalho, exposição ao pó de giz e o estresse gerado pela má remuneração.

Segundo (Marx, 1996) as condições de trabalho estão ligadas às condições de vida, onde lutar por melhores condições de trabalho no capitalismo é a luta por uma vida melhor. Temos no modo de produção capitalista a exploração da mais-valia, fato que afeta as condições de trabalho uma vez que a força de trabalho é tida como

\footnotetext{
${ }^{14}$ Disponível em https://tj-ba.jusbrasil.com.br/jurisprudencia/64062596o/mandado-de-seguranca-ms107834620178050000, acesso em I5/05/2021. is LEI № 12.772, DE 28 DE DEZEMBRO DE 2012.

Art. 16. A estrutura remuneratória do Plano de Carreiras e Cargos de Magistério Federal possui a seguinte composição:

I - Vencimento Básico, conforme valores e vigências estabelecidos no Anexo III, para cada Carreira, cargo, classe e nível; e

II - Retribuição por Titulação - RT, conforme disposto no art. 17. (Brasil, 2012).
} 
mercadoria, neste sentido, valorizar o profissional do ensino básico é oferecer melhores condições de trabalho, pois "Quando trabalhamos em condições gratificantes, gostamos do produto realizado, alguns até se apaixonam por ele, como os escritores, por exemplo. Mas quando trabalhamos subjugados, imprimimos raiva ao produto." (CODO; SAMPAIO e HITOMI, I994, p. 124).

Neste sentido, sem valorizar o profissional da educação pública do ensino básico dificilmente os princípios e preceitos constitucionais relativos à educação serão satisfeitos, consequentemente dificilmente o Brasil terá uma educação pública de qualidade.

\section{CONSIDERAÇÕES FINAIS}

Em suma, ao verificar a legislação que trata do tema "Valorização do profissional da educação pública do ensino básico" percebe-se que mesmo estando a legislação em vigor, pouco tem-se conseguido em relação a política de valorização e profissionalização docente.

Desta forma, o presente artigo abordou apenas as legislações vigentes as quais propiciam a estes trabalhadores da educação o conhecimento de seus direitos e os meios necessários para exigir sua efetivação, possibilitando a estes lutar por seus direitos, seja por vias administrativas ou judiciais, com o intuído de fazer cumprir as formas de valorização destes profissionais

Neste sentido, valorizar a educação e seus profissionais e garantir uma educação de qualidade, formadora de cidadãos ativos e preparados para o exercício da cidadania, pois sem isto o indivíduo estará fadado a alienação, conforme poema de Brecht :

O analfabeto pior é o analfabeto político. Ele não ouve, não fala, não participa dos acontecimentos políticos. Ele não sabe que o custo de vida, o preço do feijão, do peixe, da farinha, do aluguel, do sapato e do remédio dependem de decisões políticas. $O$ analfabeto político é tão burro que se orgulha e estufa o peito dizendo que odeia política. Não sabe o imbecil que, da sua ignorância política nasce a prostituta, o menor abandonado, o assaltante e o pior de todos os bandidos que é o político vigarista, pilantra, 
o corrupto e lacaio das empresas nacionais e multinacionais. ( $O$ Analfabeto Político - Bertold Brecht $)^{16}$.

\section{REFERÊNCIAS BIBLIOGRÁFICAS}

BRASIL. Constituição (1988). Constituição da República Federativa do Brasil. Disponível em: http://www.planalto.gov.br/ccivil_03/constituicao/ConstituicaoCompilado.htm. Acesso em: 06/o5/2021.

. LEI № 9.394, DE 20 DE DEZEMBRO DE 1996. Estabelece as diretrizes e bases da educação nacional: Disponível em: http://www.planalto.gov.br/ccivil_03/LEIS/L9394compilado.htm, acesso em 17/05/2021.

. LEI № ir.738, DE i6 DE JULHO DE 2008. Regulamenta a alínea "e" do inciso III do caput do art. 6o do Ato das Disposições Constitucionais Transitórias, para instituir o piso salarial profissional nacional para os profissionais do magistério público da educação básica. : Disponível em : http://www.planalto.gov.br/ccivil_03/_ato2007-2010/2008/lei/lir738.htm, acesso em 17/05/2021.

. LEI № 13.005 , DE 25 DE JUNHO DE 2014. Aprova o Plano Nacional de Educação - PNE e dá outras providências. : Disponível em : http://www.planalto.gov.br/ccivil_03/_ato20II-2014/2014/lei/113005.htm, acesso em 17/05/2021.

. LEI № 12.772, DE 28 DE DEZEMBRO DE 2012. Dispõe sobre a estruturação do Plano de Carreiras e Cargos de Magistério Federal. Disponível em : http://www.planalto.gov.br/ccivil_03/_ato2011-2014/2012/lei/Li2772compilado.htm , acesso em I7/05/2021.

CODO, W.; SAMPAIO, J. \& HITOMI, A. Indivíduo, trabalho e sofrimento: uma abordagem interdisciplinar. Petrópolis: Vozes, 2ª edição, 1994.

CUNHA, M. I. O bom professor e sua prática. Campinas SP: 2.ed. Papirus, 20 io.

GATTI, Bernardete Angelina; BARRETO, Elba Siqueira de Sá. Professores do Brasil: impasses e desafios. Brasília: UNESCO, 2009.

GENTILI, Pablo. A falsificação do consenso: simulacro e imposição na reforma educacional do neoliberalismo. Petrópolis: Vozes, 1998.

${ }_{16}$ Disponível em https://drive.google.com/file/d/rh9SGZ6kea_Fc-bDJSYQHoXKjreCL29et/view, acesso em II/05/2021 
GRAMSCI, Antonio. Os intelectuais e a organização da cultura. 2.ed. Rio de Janeiro, Civilização Brasileira, 1978.

KENSKI, V.M. O papel do Professor na Sociedade Digital. In: CASTRO, A. D. de; CARVALHO, A.M.P. de (Org.). Ensinar a Ensinar: Didática para a Escola Fundamental e Média. São Paulo; Ed. Pioneira Thompson Learning, 200I.

LEHER Roberto. "valorização do magistério" (verbete). / Organizadoras, Dalila Andrade Oliveira, Adriana Maria Cancela Duarte e Livia Maria Fraga Vieira, Dicionário de trabalho, profissão e condição docente. - Belo Horizonte: UFMG/ Faculdade de educação, 2010.

LIBÂNEO, José Carlos. Pedagogia e Pedagogos, para quê? São Paulo: Cortez, 2007.

Adeus professor, adeus professora? : novas exigências educacionais e profissão docente. 5. ed. São Paulo: Cortez, 20or.

MARX, Karl. O capital. livro Primeiro. Tomo II. Coleção Os Economistas. Trad. Regis Barbosa e Flávio R. Kothe. São Paulo: Editora Nova Cultural, 1996.

. Contribuição à crítica da economia política. São Paulo: Martins Fontes, 1977.

MARX, Karl; ENGELS, Friedrich. Textos sobre Educação e Ensino. Campinas, SP: Ed. Navegando, 20II.

A ideologia alemã. São Paulo: Boitempo, 2007.

MOCHCOVITCH, Luna Galano. Gramsci e a escola. São Paulo: Ática, 1988.

MONLEVADE, J.A.C. Movimento Sindical dos Trabalhadores e Trabalhadoras em Educação no Brasil. 3a. ed. Brasília: CNTE, 2011 , p.ir. (https://issuu.com/npc_/docs/caderno_cnte__movimento_sindical_miolo, acesso em 13/o7/2019).

OLIVEIRA, Carlos R. de. História do Trabalho. São Paulo: Editora Ática, 1987. (Série Princípios).

PERONI, Vera Maria Vidal. Múltiplas formas de materialização do privado na educação básica pública no Brasil: sujeitos e conteúdo da proposta. Revista Currículo sem Fronteiras, v. 18, n. I, p. 212-238, jan./abr. 2018. 
SADER, Emir. Prefácio a Educação Para Além Do Capital. São Paulo: Boitempo, 2008.

SAVIANI, D. Pedagogia Histórico-Crítica: Primeiras Aproximações. São Paulo: Autores Associados, 2005.

Trabalho e educação : fundamentos ontológicos e históricos. Revista Brasileira de Educação. VI2. N 34. jan/abr. 2007.

O legado educacional do século XX no Brasil. 2 ed. Campinas, SP: Autores Associados, 2006 - (Coleção Educação Contemporânea).

VICENTINI. P. P., LUGLI. R. G. História da profissão docente no Brasil: representações em Disputa. São Paulo: Cortez, 2009.

WOOD, Ellen M. A origem do capitalismo. Tradução de Vera Ribeiro. Rio de Janeiro: Jorge Zahar Editor, 20or. 